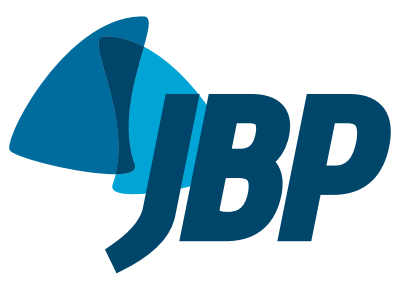

1. Universidade Federal do Ceará - UFC Fortaleza (CE) Brasil.

2. Hospital de Messejana Dr. Carlos Alberto Studart Gomes, Fortaleza (CE) Brasil.

3. Universidade de Fortaleza - UNIFOR Fortaleza (CE) Brasil.

a. (iD) http://orcid.org/0000-0003-4651-1810

b. (iD http://orcid.org/0000-0002-1964-0273

c. (iD http://orcid.org/0000-0002-9704-7299

d. (iD) http://orcid.org/0000-0002-8048-3393

e. (iD) http://orcid.org/0000-0002-4414-3164

Submitted: 5 July 2018.

Accepted: 31 March 2019.

Study carried out at the Hospital Universitário Walter Cantídio,

Universidade Federal do Ceará, and at the Hospital de Messejana Dr. Carlos Alberto Studart Gomes, Fortaleza (CE) Brasil.

\section{Assessment of religious coping in patients with COPD}

\author{
Francisco Alessandro Braga do Nascimento, ${ }^{1,2, a}$, \\ Guilherme Pinheiro Ferreira da Silva ${ }^{1,3, b}$, Geisyani Francisca Gomes Prudente ${ }^{1, c}$, \\ Rafael Mesquita ${ }^{1, d}$, Eanes Delgado Barros Pereira ${ }^{1,2, e}$
}

\begin{abstract}
Objective: To compare religious coping $(R C)$ in patients with COPD and healthy individuals, as well as to determine whether RC is associated with demographic characteristics, quality of life, depression, and disease severity in the patients with COPD. Methods: This was a cross-sectional study conducted between 2014 and 2016, involving outpatients with moderate to severe COPD seen at one of two hospitals in Fortaleza, Brazil, as well as gender- and age-matched healthy controls. The Brief RCOPE scale assessed RC in all of the participants. We also evaluated the COPD group patients regarding symptoms, quality of life, and depression, as well as submitting them to spirometry and a six-minute walk test. Results: A total of 100 patients were evaluated. The mean age was $67.3 \pm 6.8$ years, and $54 \%$ were men. In the COPD group, the mean positive RC score was significantly higher than was the mean negative RC score $(27.17$ \pm 1.60 vs. $8.21 \pm 2.12 ; p=0.001)$. The mean positive $R C$ score was significantly higher in women than in men $(27.5 \pm 1.1$ vs. $26.8 \pm 2.8 ; p=0.02)$. Negative RC scores were significantly higher in the COPD group than in the control group $(p=0.01)$. Negative $\mathrm{RC}$ showed an inverse association with six-minute walk distance (6MWD; $r=-0.3 ; p$ $<0.05)$ and a direct association with depressive symptoms $(r=0.2 ; p<0.03)$. Positive $\mathrm{RC}$ correlated with none of the variables studied. Multiple regression analysis showed that negative $\mathrm{RC}$ was associated with $6 \mathrm{MWD}$ (coefficient $=-0.009 ; 95 \% \mathrm{Cl}:-0.01$ to $-0.003)$. 6MWD explained the variance in negative $R C$ in a linear fashion. Conclusions: Patients with COPD employ negative $\mathrm{RC}$ more often than do healthy individuals. Exercise capacity and depressive symptoms are associated with negative RC.
\end{abstract}

Keywords: Religion; Spirituality; Adaptation, psychological; Quality of life; Pulmonary disease, chronic obstructive.

\section{INTRODUCTION}

COPD is a preventable and treatable disease characterized by airflow limitation and associated with an abnormal inflammatory response of the lungs to noxious particles or gases. COPD is currently considered the fourth leading cause of death worldwide. ${ }^{(1,2)}$

The systemic inflammatory component of COPD can trigger or worsen comorbidities, such as diabetes mellitus, metabolic syndrome, obstructive sleep apnea, and cachexia due to loss of lean body mass. (3) The main symptoms of COPD are dyspnea, cough, exercise intolerance, worsening of nutritional status, and increased levels of anxiety and depression. ${ }^{(4)}$

The severity of COPD and the difficulties in coping with the limitations imposed by the disease, as well as the consequent prospect of near death, may lead to varying degrees of impairment in patient quality of life (QoL)..$^{(5)}$

In this context, religiosity and spirituality can be considered coping strategies in chronic diseases. Religiosity is defined as the use of faith-related beliefs, values, practices, and individual rituals, whereas spirituality is more subjective and permeates questions about the meaning of life. ${ }^{(6)}$
Worldwide, the term religious coping (RC) is recognized as referring to behaviors adopted by the individual in order to cope with a stressful condition. RC can be perceived as having positive and negative aspects. Positive RC refers to benevolent religious appraisals and religious forgiveness, reflecting a secure relationship with God. In contrast, negative RC refers to reappraising God's powers or feeling abandoned or punished by God, reflecting a tenuous relationship with God. ${ }^{(7)}$

To date, however, few studies have addressed RC strategies in patients with COPD. RC strategies have been studied in other chronic diseases, such as cancer, chronic kidney disease, and inflammatory bowel disease, ${ }^{(8)}$ with the practice of religiosity and spirituality being found to be associated with better health status and well-being. $(9,10)$ In patients with advanced lung disease, studies indicate that $\mathrm{RC}$ is associated with higher levels of social functioning, but they also indicate that it is associated with greater psychological distress and disability. ${ }^{(11,12)}$

Following this line of reasoning, it is very important that RC be assessed because it is how individuals deal with physically and mentally stressful situations from the perspective of their health status, and because RC

Correspondence to:

Francisco Alessandro Braga do Nascimento. Rua 26, casa 26, Conjunto Beira Rio, Vila Velha, CEP 60348-230, Fortaleza, CE, Brasil.

Tel.: 5585 99973-0798. E-mail: alessandro.fisio@gmail.com

Financial support: None. 
strategies can be an integral part of patient management and treatment.

The objectives of the present study were to compare $\mathrm{RC}$ in patients with COPD and healthy individuals, as well as to determine whether $\mathrm{RC}$ is associated with demographic characteristics, quality of life measures, depression, and disease severity as defined by pulmonary function and functional exercise capacity, in the patients with COPD.

\section{METHODS}

This was a cross-sectional study conducted at the pulmonology outpatient clinics of the Federal University of Ceará Walter Cantídio University Hospital and the Dr. Carlos Alberto Studart Gomes Messejana Hospital, both of which are located in the city of Fortaleza, Brazil, between February 2014 and February 2016. The study was conducted in accordance with Brazilian National Health Council Resolution 196/96, which sets out the ethical principles for human research, and was approved by the Research Ethics Committees of the Federal University of Ceará and the Dr. Carlos Alberto Studart Gomes Messejana Hospital (Ruling no. 855.310 and Ruling no. 901.995, respectively).

We consecutively selected patients who had a confirmed diagnosis of moderate to severe COPD, on the basis of spirometry results, as defined by the Global Initiative for Chronic Obstructive Lung Disease $^{(1)}$; were between 40 and 80 years of age; and were clinically stable (no episodes of hospitalization for COPD exacerbation or infection in the three months prior to the study period). The exclusion criterion was the presence of other non-lung diseases that are considered disabling, severe, or difficult to control. Individuals for the control group were recruited from the community and, after agreeing to participate in the study, were sent to a room next to the outpatient clinic for administration of the Brief RCOPE scale. ${ }^{(13)}$ The two groups (patients and controls) were matched for gender and age. The patients with COPD were evaluated for RC, quality of life, depression, pulmonary function, and exercise capacity.

$\mathrm{RC}$ was assessed by administering the Brief RCOPE scale, ${ }^{(13)}$ which is considered a valid and reproducible instrument. This scale consists of 14 items that analyze positive aspects (7 items) and negative aspects (7 items) of RC, measured on a four-point Likert scale ranging from 1 (never) to 4 (nearly always). Scores for positive RC and negative RC can range from 7 to 28. ${ }^{(13)}$ Scores close to 7 denote less use of RC, whereas scores close to 28 indicate greater use of RC.

Health-related QoL was assessed by using three different instruments, all of which have been validated for use in Brazil. The COPD Assessment Test is an instrument specifically designed for patients with COPD, consisting of eight questions addressing the impact of COPD symptoms, and its total score ranges from 0 (least severe impact) to 40 (most severe impact). (14) The Medical Outcomes Study 36-item Short-Form
Health Survey ${ }^{(15)}$ is a generic instrument consisting of 36 items that cover 8 domains: functional capacity; role-physical; bodily pain; general health; vitality; social functioning; role-emotional; and mental health. These domains can be grouped into a physical component summary and a mental component summary. The physical and mental component summary scores can range from 0 to 100 , with higher scores indicating better general health status. The Saint George's Respiratory Questionnaire(16) is designed specifically for individuals with respiratory disease and addresses aspects related to three domains affected by the disease-symptoms, activity, and psychosocial impact. Each domain has a maximum possible score; domain scores are calculated by summing up all the scores of the individual items in each domain, and the total is expressed as a percentage $(0-100 \%)$ of the maximum possible score for that domain; higher scores indicate poorer QoL. ${ }^{(16)}$

Depressive symptoms were assessed by administering the Patient Health Questionnaire-9, ${ }^{(17)}$ which consists of 9 items scored from 0 to 3 based on the frequency of occurrence of the complaint. The total score, which is the sum of all the scores of the individual items, indicates the following: no depression (0-4 points); mild depression (5-9 points); moderate depression (10-14 points); moderately severe depression (15-19 points); and severe depression (20 or more points).

Pulmonary function was assessed by spirometry, in accordance with Brazilian guidelines, ${ }^{(18)}$ and FEV and FVC were measured. The results obtained were expressed as a percentage of predicted values, on the basis of Brazilian population reference values. ${ }^{(19)}$

Exercise capacity was measured with the six-minute walk test, conducted in accordance with the European Respiratory Society/American Thoracic Society guidelines. ${ }^{(20)}$ The patient was encouraged to walk as far as possible, in six minutes, on a 30-m level corridor. At the end of the test, the examiner recorded the total distance covered in six minutes, that is, the six-minute walk distance (6MWD)

Data were analyzed with SPSS Statistics software, version 17.0 (SPSS Inc., Chicago, IL, USA). Descriptive analysis was performed by calculating absolute frequencies, relative frequencies, means and standard deviations, or medians and interquartile ranges (IQRs). Normally distributed numerical variables were compared by using the Student's t-test for independent samples. Non-normally distributed numerical variables were compared by using the Mann-Whitney $U$ test. Categorical variables were compared by using the Chi-square test. Correlations between numerical variables were analyzed with Pearson's correlation coefficient. Multivariate linear regression analysis was performed to identify factors potentially related to $\mathrm{RC}$, and independent variables included in the multivariate model were those with a significance level $<5 \%$ in the univariate analysis. Statistical significance was set at $p<0.05$. 


\section{RESULTS}

\section{General characteristics}

A total of 100 patients with COPD participated in the study. The mean age was $67.3 \pm 6.8$ years. The patients were predominantly male $(54 \%)$, literate $(68 \%)$, and Catholic (77\%). Comorbidity was present in $36 \%$ of the sample (Table 1 ). The mean positive RC score and the mean negative $\mathrm{RC}$ score were $27.17 \pm 1.60$ and 8.21 \pm 2.12 , respectively. Positive $\mathrm{RC}$ scores were found to be significantly higher than were negative RC scores $(p=0.01)$, demonstrating that the patients with COPD more often employed positive RC strategies to deal with their disease. The sociodemographic and clinical characteristics of the sample are described in Table 1.

When assessing RC among patients with COPD by gender, level of education, religion, and presence of comorbidities, we found a significant difference only for gender, showing that women employed positive $\mathrm{RC}$ more often than did men $(27.5 \pm 1.1$ vs. $26.8 \pm$ 2.8; $\mathrm{p}=0.02$ ).

\section{Religious coping in patients with COPD and healthy individuals}

No statistically significant difference was found in positive RC between patients with COPD and healthy individuals, with medians [IQR] of 28 [27-28] and 28 [28-28], respectively $(p=0.08)$. However, negative $\mathrm{RC}$ scores were significantly higher in patients with COPD than in healthy individuals: 8 [7-8] and 7 [7-7], respectively $(p=0.01)$.

\section{Factors associated with religious coping in patients with COPD}

Negative RC showed an inverse association with 6MWD $(r=-0.3 ; p<0.05)$ and a direct association with depressive symptoms $(r=0.2 ; p<0.03$; Table 2 ). No significant correlations were observed between negative RC and any of the other variables studied. Positive RC correlated significantly with none of the variables studied.

Multiple linear regression analysis was performed to identify independent variables strongly associated with negative RC (dependent variable). The independent variables selected were statistically significant in the univariate analysis. The model was built taking into account confounding variables and collinearity. The variables that explained the variance in negative RC in a linear fashion were identified by using a backward stepwise process (Table 3 ). The 6MWD was most strongly associated with negative $\mathrm{RC}$ (coefficient = $-0.009 ; 95 \% \mathrm{CI}:-0.01$ to -0.003 ), which explained $35 \%$ of the variance in negative RC.

\section{DISCUSSION}

The present study showed that patients with COPD more significantly employ positive RC to deal with their disease. The use of a positive strategy reflects a secure relationship with a transcendental force and a benevolent
Table 1. Sociodemographic characteristics and clinical variables of the sample of patients with COPD. ${ }^{a}$

\begin{tabular}{|c|c|}
\hline Variable & $(N=100)$ \\
\hline Age, years & $67.3 \pm 6.8$ \\
\hline \multicolumn{2}{|l|}{ Gender } \\
\hline Male & $54(54)$ \\
\hline Female & $46(46)$ \\
\hline \multicolumn{2}{|l|}{ Marital status } \\
\hline Single & $7(7)$ \\
\hline Married & $67(67)$ \\
\hline Separated & $9(9)$ \\
\hline Widowed & $17(17)$ \\
\hline \multicolumn{2}{|l|}{ Level of education } \\
\hline Literate & $68(68)$ \\
\hline Illiterate & $32(32)$ \\
\hline \multicolumn{2}{|l|}{ Religion } \\
\hline Catholic & $77(77)$ \\
\hline Non-Catholic & $23(23)$ \\
\hline $\mathrm{BMI}, \mathrm{kg} / \mathrm{cm}^{2}$ & $25 \pm 4.8$ \\
\hline \multicolumn{2}{|l|}{ Comorbidities } \\
\hline Yes & $36(36)$ \\
\hline No & $64(64)$ \\
\hline \multicolumn{2}{|l|}{ Spirometry } \\
\hline Post-BD FEV,$\%$ of predicted & $45.4 \pm 12.6$ \\
\hline Post-BD FVC, \% of predicted & $61.3 \pm 15.1$ \\
\hline 6MWD, m & $368.5 \pm 76.1$ \\
\hline \multicolumn{2}{|l|}{ Religious coping } \\
\hline Positive & $28[27-28]$ \\
\hline Negative & $7[7-8]$ \\
\hline CAT & $18.6 \pm 8.2$ \\
\hline \multicolumn{2}{|l|}{ SGRQ } \\
\hline Symptoms & $45.4 \pm 21.1$ \\
\hline Activity & $64.4 \pm 20.9$ \\
\hline Psychosocial impact & $43.7 \pm 19.8$ \\
\hline Total & $51.7 \pm 16.01$ \\
\hline \multicolumn{2}{|l|}{ SF-36 } \\
\hline PCS & $39.25 \pm 15.28$ \\
\hline MCS & $51.28 \pm 11.83$ \\
\hline PHQ-9 & $9 \pm 5.8$ \\
\hline
\end{tabular}

BMI: body mass index; BD: bronchodilator; 6MWD: six-minute walk distance; CAT: COPD Assessment Test; SGRQ: Saint George's Respiratory Questionnaire; SF-36: Medical Outcomes Study 36-item Short-Form Health Survey; PCS: physical component summary; MCS: mental component summary; and PHQ-9: Patient Health Questionnaire-9. ${ }^{\text {VValues expressed as }}$ $\mathrm{n}(\%)$, mean $\pm \mathrm{SD}$, or median [interquartile range].

view of the world. Negative RC (spiritual conflict) was less common in the sample. However, when used, it was found to be associated with disease severity as measured by 6MWD and with psychological distress.

When comparing RC in patients with COPD and healthy individuals, we found that both groups had similar positive RC scores. However, we found that negative RC scores were significantly higher in the COPD group. This reflects the spiritual suffering of the patients who, in the face of illness, feel dissatisfaction 
Table 2. Correlation between religious coping and demographic and clinical data in patients with COPD.

\begin{tabular}{lcccc}
\multicolumn{1}{c}{ Variable } & Positive RC & \multicolumn{2}{c}{ Negative RC } \\
Age & $\mathbf{r}$ & $\mathbf{p}$ & $\mathbf{r}$ & $\mathbf{p}$ \\
Post-BD FEV ${ }_{1}$ (\% of predicted) & -0.02 & 0.8 & -0.12 & 0.2 \\
6MWD & 0.03 & 0.7 & -0.05 & 0.6 \\
SGRQ & 0.18 & 0.06 & -0.34 & 0.04 \\
$\quad$ Symptoms & & & 0.2 \\
$\quad$ Activity & -0.06 & 0.5 & 0.11 & 0.2 \\
$\quad$ Psychosocial impact & 0.03 & 0.7 & 0.10 & 0.5 \\
$\quad$ Total & -0.08 & 0.4 & -0.05 & 0.6 \\
CAT & -0.06 & 0.5 & 0.04 & 0.6 \\
SF-36 & -0.03 & 0.7 & -0.04 & 0.1 \\
$\quad$ PCS & & & 0.1 \\
$\quad$ MCS & -0.03 & 0.7 & -0.14 & 0.03 \\
PHQ-9 & 0.06 & 0.5 & -0.10 & 0.21 \\
\hline
\end{tabular}

RC: religious coping; BD: bronchodilator; 6MWD: six-minute walk distance; SGRQ: Saint George's Respiratory Questionnaire; CAT: COPD Assessment Test; SF-36: Medical Outcomes Study 36-item Short-Form Health Survey; PCS: physical component summary; MCS: mental component summary; and PHQ-9: Patient Health Questionnaire-9.

Table 3. Multivariate linear regression analysis of negative religious coping and clinical variables of the sample.

\begin{tabular}{|c|c|c|c|c|c|}
\hline Outcome/Variable & Coefficient & Standard error & $\mathbf{t}$ & $\mathbf{p}$ & $95 \% \mathrm{Cl}$ \\
\hline \multicolumn{6}{|l|}{ Negative religious coping } \\
\hline Constant & 11.07 & 1.23 & 8.94 & $<0.01$ & $8.61-13.52$ \\
\hline 6MWD & -0.009 & 0.003 & -3.01 & 0.003 & -0.01 to -0.003 \\
\hline
\end{tabular}

6MWD: six-minute walk distance.

with God, which leads them to redefine the stressor as a divine punishment. ${ }^{(21)}$

In the present study, women were found to employ positive RC more often than men. Culturally, women are more resilient and, therefore, use positive RC strategies to deal with stress. ${ }^{(22)}$ In a recent systematic review, Veit et al. ${ }^{(23)}$ reported greater use of positive $\mathrm{RC}$ in women with breast cancer.

The results of the present study demonstrate that there is a statistically significant correlation between negative RC and depressive symptoms in patients with COPD, which corroborates the findings of previous studies involving patients with emphysema ${ }^{(9)}$ and patients with chronic lung disease being evaluated for lung transplantation. ${ }^{(11)}$ In the latter study, ${ }^{(11)}$ the authors pointed out that, although the patients were severely ill, no significant levels of depression were found, which was explained by the prospect of cure after the transplantation process. Yohannes et al. (24) stated that the mechanism determining the common association of COPD with depression has not yet been properly identified.

In the present study, negative RC scores showed an inverse and statistically significant correlation with exercise capacity as measured by 6MWD, which is an important predictor of disease severity. ${ }^{(25)}$ This demonstrates that the impairment caused by COPD seems to have an important relationship with the coping strategy used by the patient. Burker et al. (26) reported frequent use of negative RC strategies in the face of important outcomes in patients with chronic lung disease being evaluated for lung transplantation.

No significant correlations were found between RC and pulmonary function or QoL, which is in contrast to the findings of previous studies. ${ }^{(9,27)}$ Pedersen et al. ${ }^{(27)}$ stated that negative RC was associated with poor QoL in patients with COPD. Perhaps one reason why our study did not demonstrate such an association was that our patients rarely employed negative RC.

The results of the present investigation show health care professionals the importance of assessing religiosity in patients with COPD who are treated in health care facilities, especially to identify those who employ negative $\mathrm{RC}$, because this is related to psychological distress and disease severity. Following this line of reasoning, research addressing $\mathrm{RC}$ in a focused and specific manner should include the search for spiritual and religious support. ${ }^{(27)}$

Some strengths of the present study include the assessment of RC strategies in patients with COPD, a topic that has been addressed by few studies, and the determination of whether these strategies are associated with clinical variables. In addition, the study supports that RC can be one more strategy in approaching these patients and adds to the current literature by providing one more source of information for future studies using a similar approach. Among the limitations of the study is its cross-sectional design, which precludes further causal inferences. Since this was a convenience sample, generalization is unwarranted. 
In addition, the lack of a qualitative approach can also be considered a limitation, given that combining such an approach with the quantitative method would allow a more detailed understanding of patient perceptions of how religiosity is experienced and dealt with in the context of their health status.

\section{REFERENCES}

1. Vogelmeier CF, Criner GJ, Martínez FJ, Anzueto A, Barnes PJ, Bourbeau J, et al. Global Strategy for the Diagnosis, Management, and Prevention of Chronic Obstructive Lung Disease 2017 Report: GOLD Executive Summary. Eur Respir J. 2017 49(3). pii: 1700214. https://doi.org/10.1183/13993003.00214-2017

2. Lozano R, Naghavi M, Foreman K, Lim S, Shibuya K, Aboyans V, et al. Global and regional mortality from 235 causes of death for 20 age groups in 1990 and 2010: a systematic analysis for the Global Burden of Disease Study 2010. Lancet. 2012;380(9859):2095-128. https:// doi.org/10.1016/S0140-6736(12)61728-0

3. Barnes PJ, Celli BR. Systemic manifestations and comorbidities of COPD. Eur Respir J. 2009;33(5):1165-85. https://doi. org/10.1183/09031936.00128008

4. Stucki A, Stucki G, Cieza A, Schuurmans MM, Kostanjsek N, Ruof J. Content comparison of health-related quality of life instruments for COPD. Respir Med. 2007;101(6):1113-22. https://doi.org/10.1016/j. rmed.2006.11.016

5. Blinderman CD, Homel P, Billings JA, Tennstedt S, Portenoy RK. Symptom distress and quality of life in patients with advanced chronic obstructive pulmonary disease. J Pain Symptom Manage. 2009;38(1):115-23. https://doi.org/10.1016/j. jpainsymman.2008.07.006

6. Harrison MO, Koenig HG, Hays JC, Eme-Akawari AG, Pargament KI. The epidemiology of religious coping: a review of recent literature. Int Rev Psychiatr. 2001;13(2):86-93. https://doi. org/10.1080/09540260124356

7. Pargament KI, Smith BW, Koenig HG, Perez L. Patterns of positive and negative religious coping with major life stressors. J Sci Study Relig. 1998;37(4):710-724. https://doi.org/10.2307/1388152

8. Freitas TH, Hyphantis TN, Andreoulakis E, Quevedo J, Miranda $\mathrm{HL}$, et al. Religious coping and its influence on psychological distress, medication adherence, and quality of life in inflammatory bowel disease. Braz J Psychiatry. 2015;37(3):219-27. https://doi. org/10.1590/1516-4446-2014-1507

9. Green MR, Emery CF, Kozora E, Diaz PT, Make BJ. Religious and spiritual coping and quality of life among patients with emphysema in the National Emphysema Treatment Trial. Respir Care. 2011;56(10):1514-21. https://doi.org/10.4187/respcare.01105

10. Saffari M, Pakpour AH, Naderi MK, Koenig HG, Baldacchino DR, Piper CN. Spiritual coping, religiosity and quality of life: a study on Muslim patients undergoing haemodialysis. Nephrology (Carlton). 2013;18(4):269-75. https://doi.org/10.1111/nep.12041

11. Burker EJ, Evon DM, Sedway JA, Egan T. Religious coping, psychological distress, and disability among patients with end-stage pulmonary disease. J Clin Psychol Med Settings. 2004;11(3):179193. https://doi.org/10.1023/B:JOCS.0000037612.31730.56

12. Maselko J, Kubzansky L, Kawachi I, Staudenmayer J, Berkman L. Religious service attendance and decline in pulmonary function in a high-functioning elderly cohort. Ann Behav Med. 2006;32(3):245-53. https://doi.org/10.1207/s15324796abm3203_11

13. Pargament KI, Feuille M, Burdzy D. The Brief RCOPE: Current Psychometric Status of a Short Measure of Religious Coping. Religions. 2011;2(1):51-76. https://doi.org/10.3390/rel2010051
14. Silva GP, Morano MT, Viana CM, Magalhães CB, Pereira ED. Portuguese-language version of the COPD Assessment Test: validation for use in Brazil. 2013;39(4):402-8. https://doi.org/10.1590/ S1806-37132013000400002

15. Ciconelli RM, Ferraz MB, Santos W, Meinão I, Quaresma MR Tradução para a língua portuguesa e validação do questionário genérico de avaliação de qualidade de vida SF-36 (Brasil SF-36). Rev Bras Reumatol. 1999;39(3):143-50. http://dx.doi.org/10.1590/S010235862000000300004

16. Sousa TC, Jardim JR, Jones P. Validation of the Saint George's Respiratory Questionnaire in patients with chronic obstructive pulmonary disease in Brazil [Article in Portuguese]. J Pneumol. 2000;26(3):119-28

17. Santos IS, Tavares BF, Munhoz TN, Almeida LS, Silva NT, Tams BD et al. Sensitivity and specificity of the Patient Health Questionnaire-9 (PHQ-9) among adults from the general population [Article in Portuguese]. Cad Saude Publica. 2013;29(8):1533-43. https://doi. org/10.1590/S0102-311X2013001200006

18. Sociedade Brasileira de Pneumologia. Diretrizes para Testes de Função Pulmonar. J Pneumol. 2002;28(Suppl 3):S1-S238.

19. Pereira CA, Barreto SP, Simões JG, Pereira FW, Gerstler JG, Nakatami J. Valores de referência para a espirometria em uma amostra da população brasileira adulta. J Pneumol. 1992;18(1):10-22.

20. Holland AE, Spruit MA, Troosters T, Puhan MA, Pepin V, Saey D, et al. An official European Society/American Thoracic Society technical standard: field walking tests in chronic respiratory disease. Eur Respir J. 2014;44(6):1428-46. https://doi.org/10.1183/09031936.00150314

21. Schleder LP, Parejo LS, Puggina AC, Silva MJP. Espiritualidade dos familiares de pacientes internados em unidade de terapia intensiva. Acta Paul Enferm. 2013;26(1):71-8. https://doi.org/10.1590/S0103 21002013000100012

22. Canaval GE, González MC, Sánchez MO. Espiritualidad y resiliencia en mujeres maltratadas que denuncian su situación de violencia de pareja. Colombia Med. 2007;38(Suppl 2):72-78.

23. Veit CM, Castro EK. Spiritual/religious coping and breast cancer: A systematic literature review [Article in Portuguese]. Psicol Saude Doenças. 2013;14(1):1-22. https://doi.org/10.15309/13psd140101

24. Yohannes AM, Alexoupolos GS. Depression and anxiety in patients with COPD. Eur Respir Rev. 2014;23(133):345-9. https://doi. org/10.1183/09059180.00007813

25. Dajczman E, Wardini R, Kasymjanova G, Préfontaine D, Baltzan MA, Wolkove N. Six minute walk distance is a predictor of survival in patients with chronic obstructive pulmonary disease undergoing pulmonary rehabilitation. Can Respir J. 2015;22(4):225-9. https://doi. org/10.1155/2015/280187

26. Burker EJ, Evon DM, Sedway JA, Egan T. Religious and nonreligious coping in lung transplant candidates: does adding god to the picture tell us more? J Behav Med. 2005;28(6):513-26. https://doi. org/10.1007/s10865-005-9025-4

27. Pedersen HF, Pargament KI, Pedersen CG, Zachariae R. Religious coping and quality of life among severely ill lung patients in a secular society. Int J Psychol Relig. 2013;23(3):188-203. https://doi.org/10.10 $80 / 10508619.2012 .728068$ 